\title{
Vestigios arqueológicos incaicos en las cumbres de la zona atacameña
}

Gustavo Le Paige ${ }^{1}$

\section{Introducción}

Desde hace un tiempo hemos tenido la intención de entregar a nuestros lectores algunas evidencias arqueológicas del Periodo Inca en la zona atacameña. Cuestión que habíamos adelantado ya en algo en el número 5 de esta revista (Le Paige 1977). Sin embargo, esa vez además de planos, croquis y fotografías presentamos el trabajo sobre una hipótesis de distribución espacial y cómo ocuparon los incas estas cumbres. Sin duda se trata de funciones de carácter sagrado y sirvieron además como medio de comunicación y respeto religioso por parte de los incas. Además, en nuestra zona este periodo recién empieza a conocerse a la luz de nuevos trabajos sistemáticos como es el caso de la excavación del tambo de Catarpe por parte de un equipo chilenonorteamericano. Antes, los planos de Mostny (1949) nos habían señalado la distribución y cantidad de habitaciones del pucara de Quitor. Este fue ocupado finalmente por los incas, y seguramente reunió poblaciones anteriores.

Decimos esto, pues hay datos para estudiar los contactos incas entre los pueblos radicados en nuestros oasis al pie de las cumbres que luego comentaremos.

En las láminas que acompañan al texto se puede observar la ubicación y distribución aproximada de cada uno de los conjuntos arquitectónicos que reconociéramos, y a los cuales les hemos asignado un tiempo inca, aunque bien pudieron ser anteriores y reocupados posteriormente por la gente del incario. Sin embargo, hasta ahora todo parece indicar que pertenecen sólo a este período cultural.

Es común para cada uno de los conjuntos, que a las estructuras ceremoniales o habitaciones comunes les

1 Museo Arqueológico de San Pedro de Atacama, Universidad del Norte, San Pedro de Atacama, CHILE. acompañen fogones y rumas de leña la que a veces encontramos diseminada en diferentes sectores y a diferentes alturas en nuestras ascensiones, lo cual parece indicar que se trató de mantener una buena cantidad de madera para cualquier ocasión.

En relación al material e información que tenemos, la cumbre del volcán Licancabur es la que más nos ha aportado. Esta cumbre fue ascendida en 1886 por una expedición francesa dando a conocer por primera vez las ruinas y leña que se encontraban en la cima. Cuestión que fue corroborada los años 1956 y 1972 por un equipo de militares y el autor, confirmando además la pérdida de una estatuilla donada al Museo de Historia Natural de Santiago por la expedición de 1886 , a la vez que logramos describir los conjuntos ceremoniales (Figuras 1, 2, 3 y 4), cuestión que fue realizada por el mayor Rosende.

A los pies de la cumbre del Licancabur y 500 m más arriba se encuentran las habitaciones ceremoniales, mientras que a mayor altura se ubican algunas estructuras presumiblemente de culto (huacas). El pueblo Licancabur está constituido por un patio central de $10 \mathrm{~m} \times 4 \mathrm{~m}$ rodeado de dependencias. Aquí recolectamos dos tipos de cerámica: una de pasta colorada al parecer del tipo "concho de vino", similar a la hallada en Toconao Oriente y también en el pucara de Quitor. El segundo tipo corresponde a una alfarería de tratamiento muy fino y pasta colorada, anaranjada, blanca, concho de vino, con dibujos pintados y asas en forma de pato (tipo inca). Sobre $5100 \mathrm{~m}$ se hallan las habitaciones ceremoniales, con divisiones muy bien definidas, además de puertas de acceso y paredes bien conservadas. Se trata de dos habitaciones y un fogón (Figura 3).

Tanto la ubicación, distribución como las dimensiones de cada una de las estructuras se puede apreciar en el conjunto de figuras realizadas por el mayor Rosende.

Algo más sobre el Licancabur es la leyenda que circula sobre sus bodas con el Quimal y su venganza contra los violadores de su cumbre. 


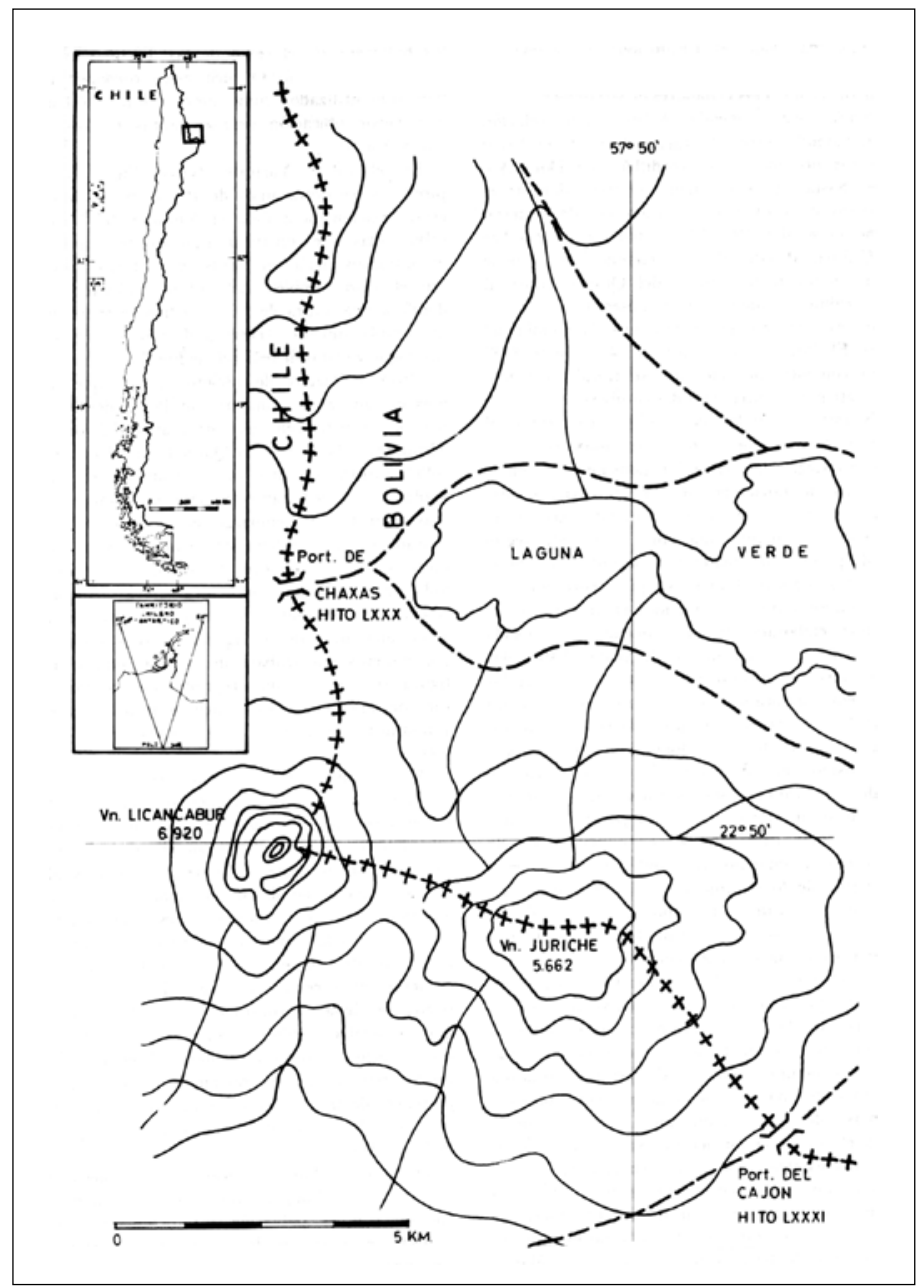

Figura 1. Ubicación del volcán Licancabur.

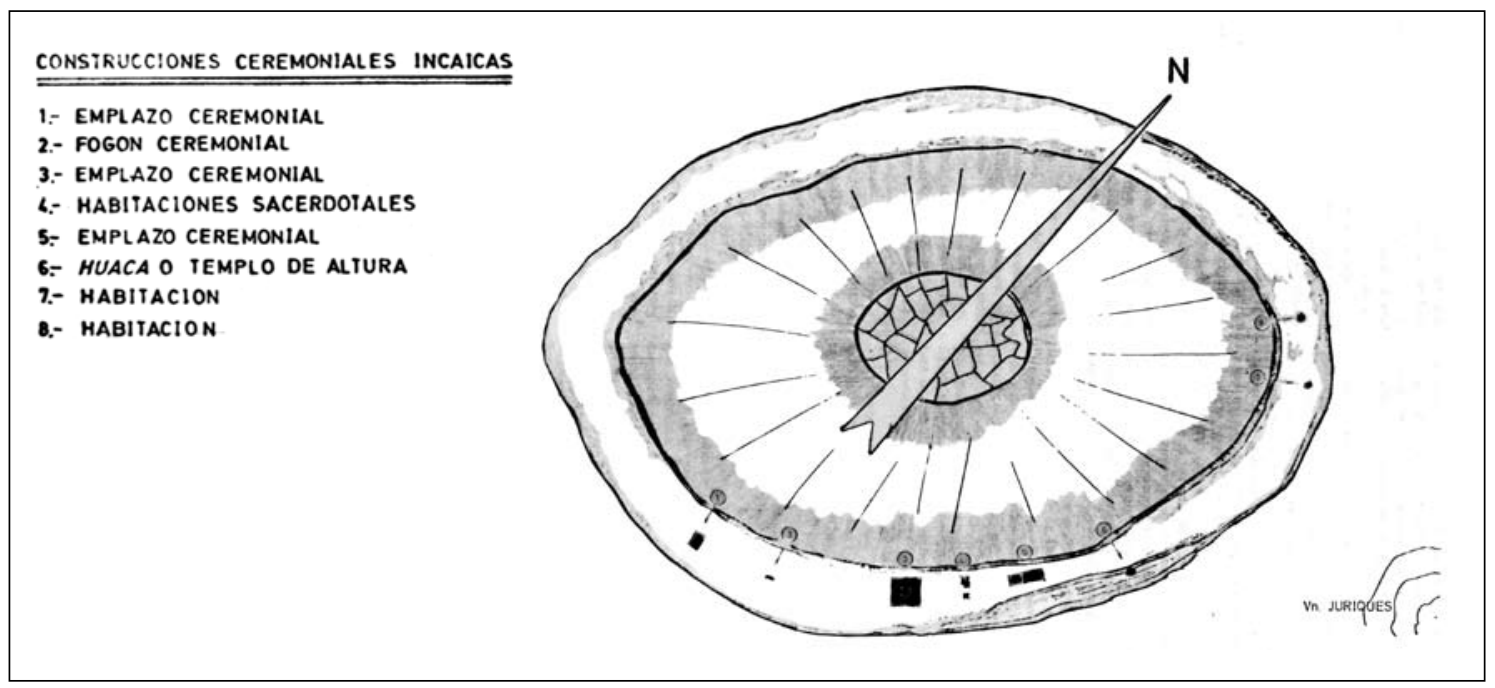

Figura 2. Cráter del volcán Licancabur. Escala 1: 1125. 

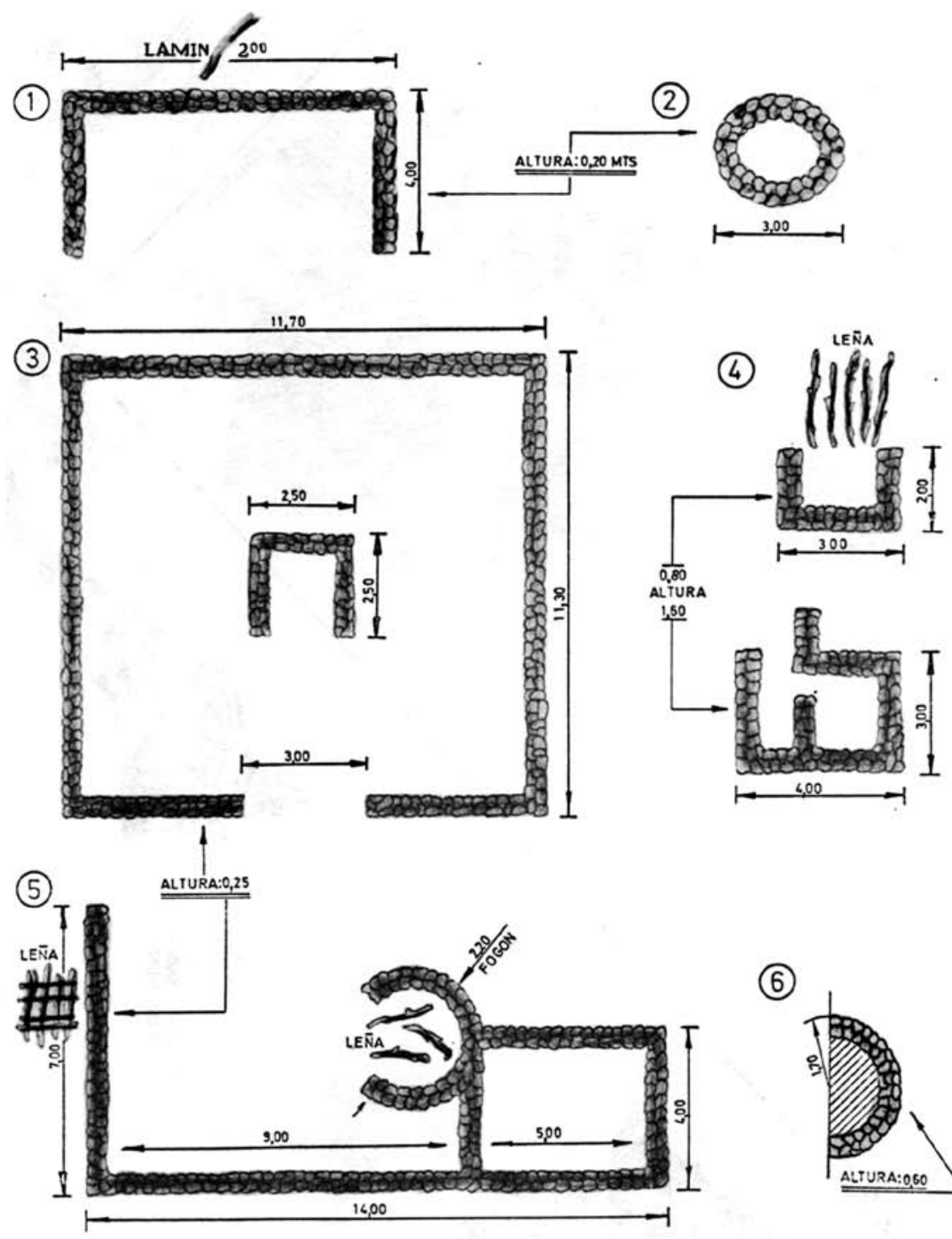

(6)

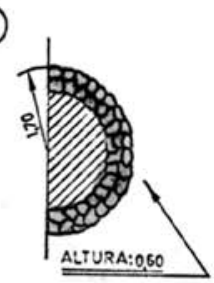

(7)

(8)

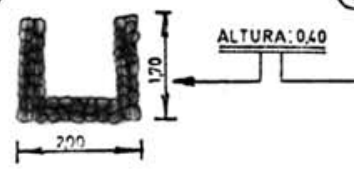

$\begin{array}{ll}\text { 1. EMPLAZO CEREMONIAL } & \text { 5- EMPLAZO CEREMONIAL } \\ \text { 2.- FOGON CEREMONIAL } & \text { 5: HUACA O TEMPLO DE ALTURA } \\ \text { 3.- EMPLAZO CEREMONIAL } & \text { 7- HAEITACION }\end{array}$

ESCALA $1: 125$

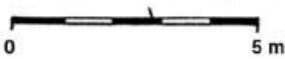

6- HABITACIONES SACERDOTALES 8-HABITACION

Figura 3. Construcciones incaicas en el borde del cráter del Licancabur (5920 m). 


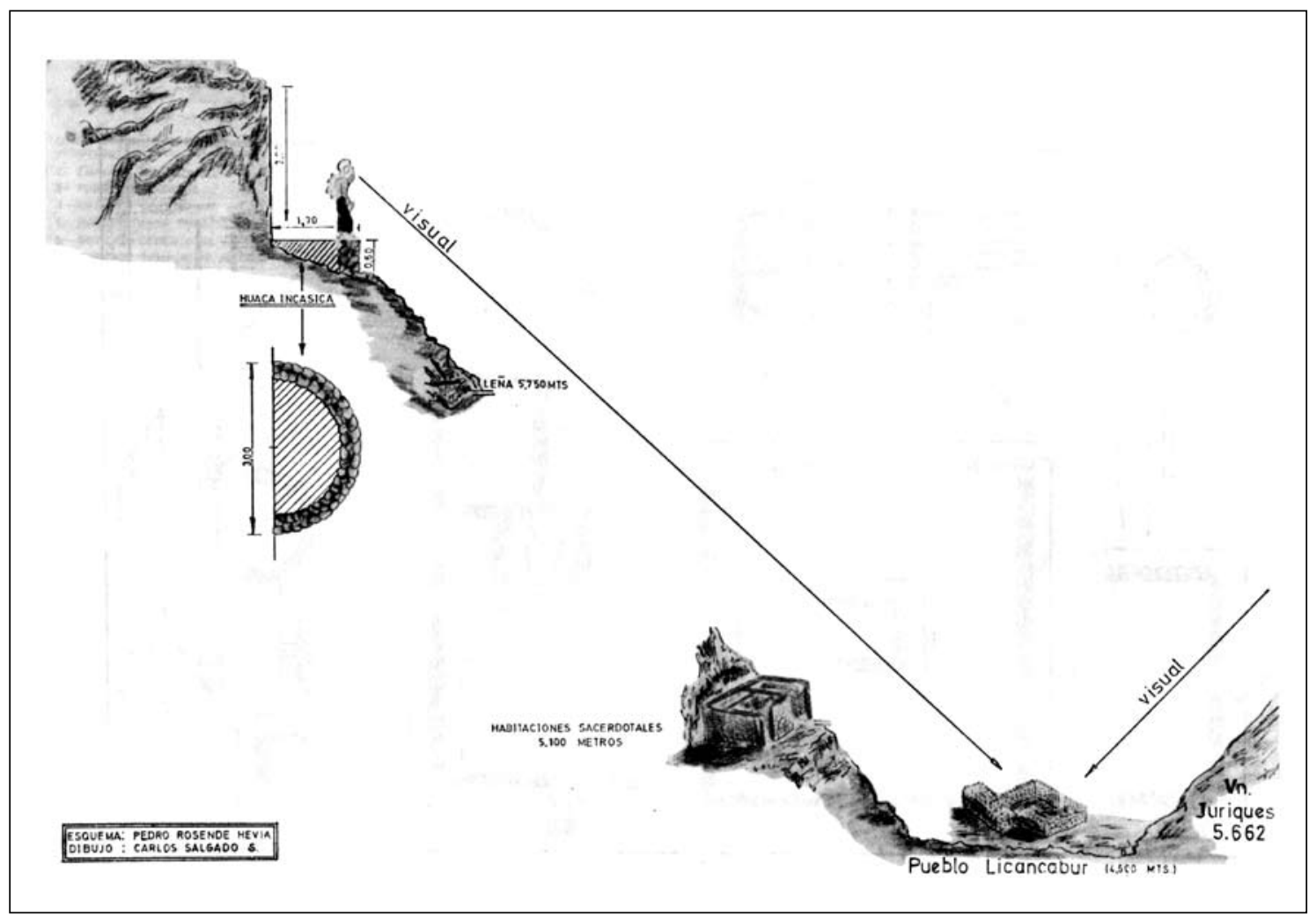

Figura 4. Estructuras incaicas en la vertiente oriental del volcán Licancabur. Se destaca en la base del volcán los recintos ceremoniales denominados pueblo Licancabur.

Según esta leyenda habría una relación matrimonial entre el Licancabur y el cerro Quimal ubicado en la cordillera de Domeyko, pues hasta ahora se puede observar durante el solsticio de verano y el equinoccio de invierno cómo la sombra del Licancabur se pone sobre el Quimal al salir el sol y cuando éste se pone hacia occidente la sombra del Quimal cubre al Licancabur. Además una observación interesante es que cuando se descubrió la momia del cerro El Plomo en la zona Central, la gente de la zona comentó diciendo que se trataba del hijo del matrimonio entre estas dos cumbres.

Nuestro segundo ascenso lo realizamos al volcán Lascar, pero sin resultados positivos. Sin embargo, la tercera expedición al volcán Pili (noviembre 24 de 1971), permitió mapear y reconocer cuatro plataformas ceremoniales, formando una hoja de trébol. Se rescataron dos figuras humanas que representan a un hombre y mujer, realizados en miniatura, un hombre elaborado en una concha color rosada (Spondylus), y una mujer de plata. Estas dos estatuillas se encontraban vestidas con tejidos ricamente decorados; la del hombre tenía un penacho de plumas negras sobre su cabeza, una chuspa en tejido de fondo café con sus bordes cosidos en hilo trenzado de color rojo y verde con franjas listadas color café, el manto sólo de color café oscuro y el poncho o túnica de color café con bordes embarrilados de colores rojo y amarillo (Figura 4a, b, c). En cambio la mujer tenía un tejido de fondo rojo con una decoración listada en rojo, café y amarillo, pero haciendo figuras en zigzag. El penacho fue elaborado con plumas rojas (Figura 4d).

En diciembre de 1972, siguiendo nuestra programación de ascensiones a las cumbres de la zona atacameña, alcanzamos la cumbre del volcán Pular; en ella encontramos una estructura ceremonial central rodeada de rumas de leña y un fogón hacia el lado noroeste, además de una habitación circular (pirca) hacia el sur de la estructura. Nos llamó la atención encontrar dos ratones en la cima de este volcán, uno de ellos en el interior de la estructura ceremonial y el otro inmediatamente fuera de ella. Al parecer, estos roedores llegaron aquí en los atados de leña, situación que es similar a los hallazgos en el cerro las Tórtolas en la provincia 


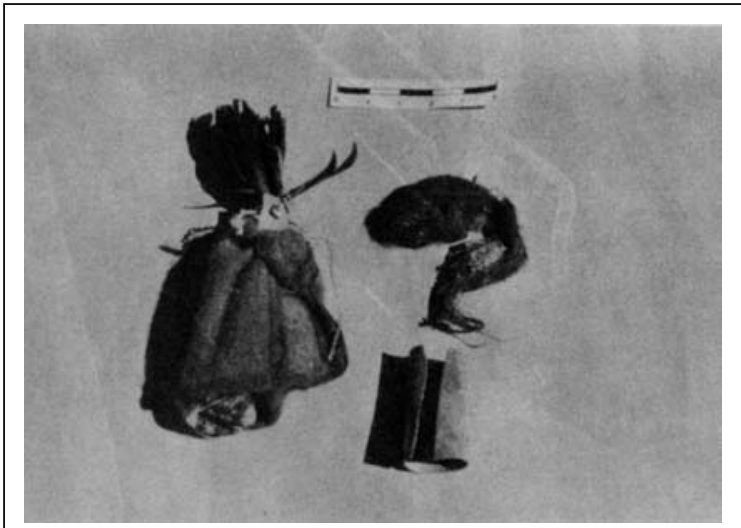

$\mathrm{a}$
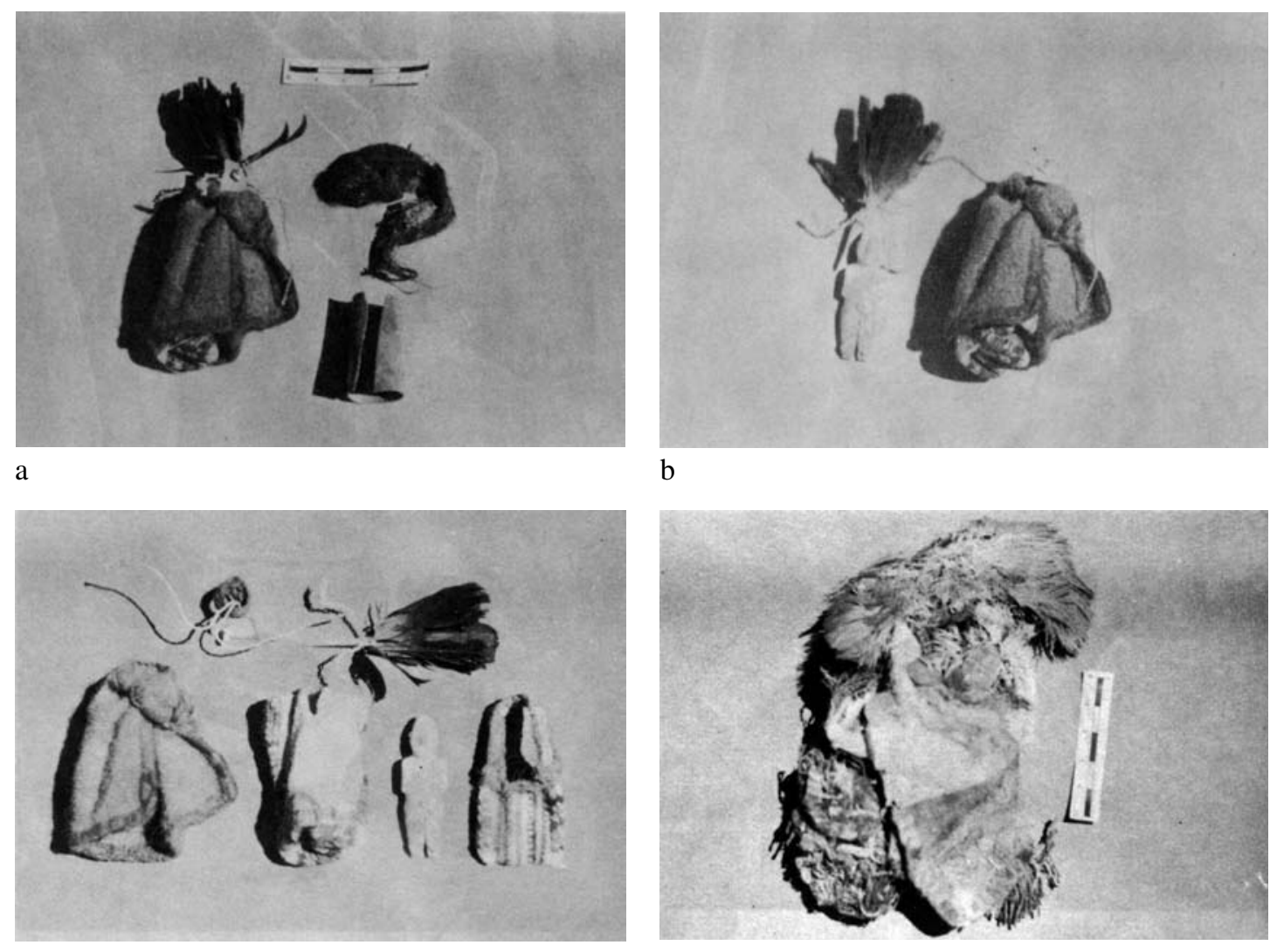

b

c

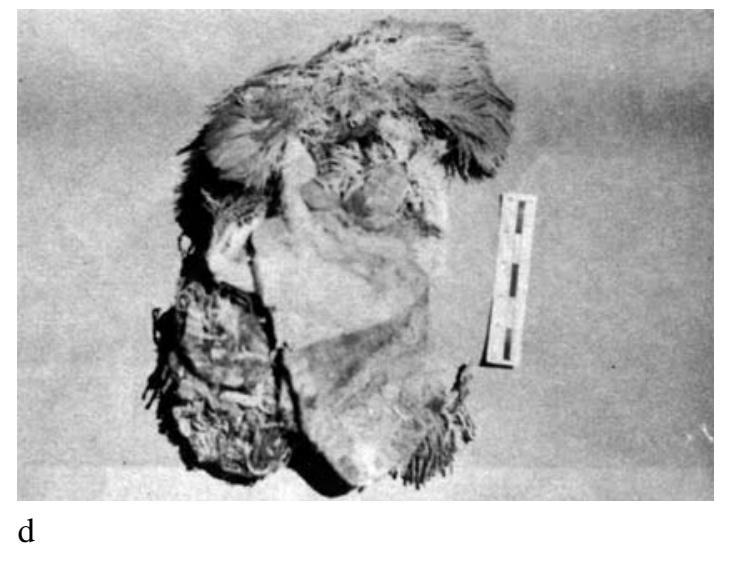

Figura 4. Ofrendas incaicas de la cumbre del volcán Pili. a, b y c) Figura masculina con su envoltorio;

d) Figura femenina con su envoltorio.

de Elqui; o bien podrían haber sido parte del ritual (Figuras 5, 6, 7, 8, 9, 10 y 11).

En el volcán Yariques (Figura 12), la pirca que encontráramos de $10 \mathrm{~m} \mathrm{x} 4 \mathrm{~m}$ parece estar relacionada a todo el conjunto del Licancabur, más que constituir algo aparte. Aquí no encontramos leña ni otras estructuras, como fue el caso también del volcán Colorado, en donde a una altura de $5732 \mathrm{~m}$.snm se encuentra un emplazamiento ceremonial con su respectivo fogón y restos de leña (Figura 13).

Otros hallazgos de recintos incas, que hemos ubicado en la zona de San Pedro de Atacama, los constituyen las estructuras del volcán Miniques y las del cerro Quimal. En el primero sólo se trata de una pirca levantada en una explanada inmediatamente bajo la cumbre, sin más elementos. Sin embargo, en el cerro Quimal, ubicado en la cordillera de
Domeyko, y al cual fuéramos en noviembre de 1976, encontramos todo un conjunto estructural inca. Además rescatamos de manos de un habitante de la zona una de 14 figuras votivas halladas por mineros que trabajaron en esta cumbre. La figura es una reproducción en miniatura de una llama, puesta dentro de una caja de cuero en miniatura (Figuras 14 y 15).

Al terminar este artículo deseamos señalar que nuestras observaciones se han realizado en el triángulo compuesto por el volcán Miño por el norte, el Llullaillaco por el sur y el cerro Quimal por el oeste. Esta región corresponde al espacio donde se desarrolló la cultura atacameña, y las cumbres antes mencionadas fueron adoradas por las nuevas costumbres religiosas del imperio incaico. Estas cumbres sirvieron para rendir un culto al sol, pero los restos de leñas encontrados permiten suponer que realizaban señales, como un sistema de comunicación. Aunque 


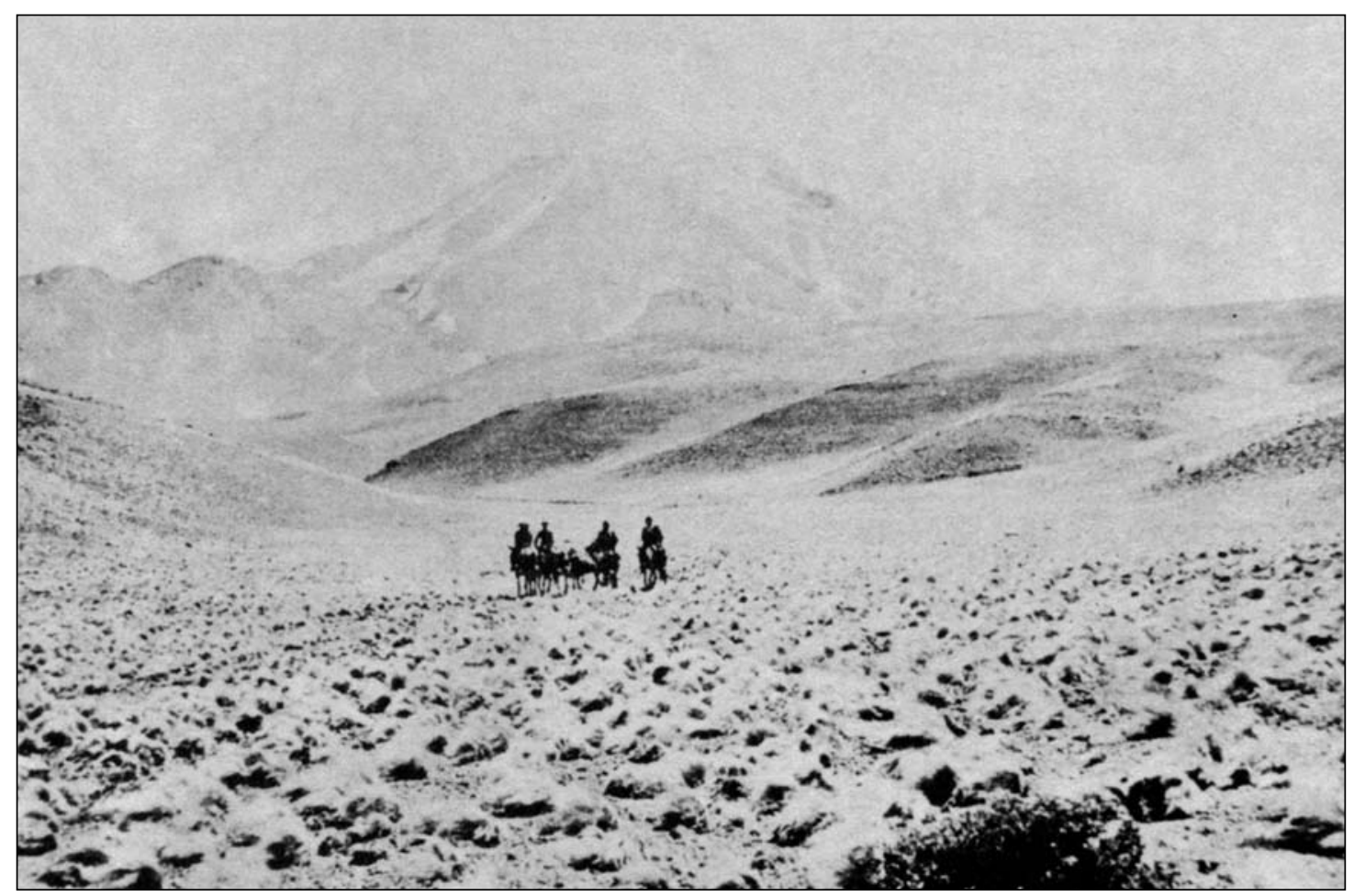

Figura 5. Panorama general del volcán Pular, de $6220 \mathrm{~m}$.

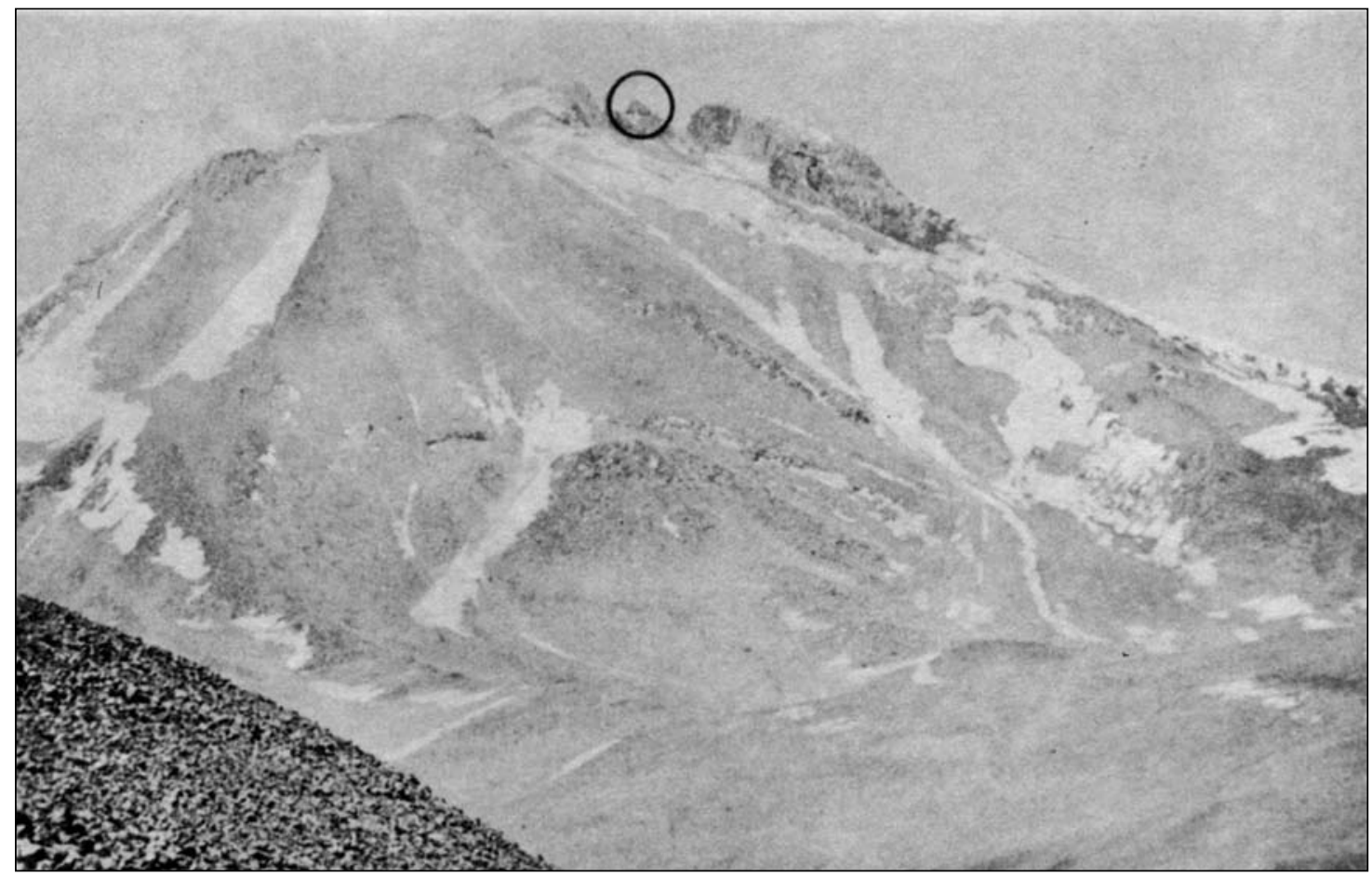

Figura 6. Fotografía del volcán Pular, tomada con teleobjetivo. El círculo señala el lugar donde se encuentra el conjunto ceremonial. Corresponde a una cumbre menor orientada hacia el Salar de Atacama y mira directamente al cerro Quimal. 


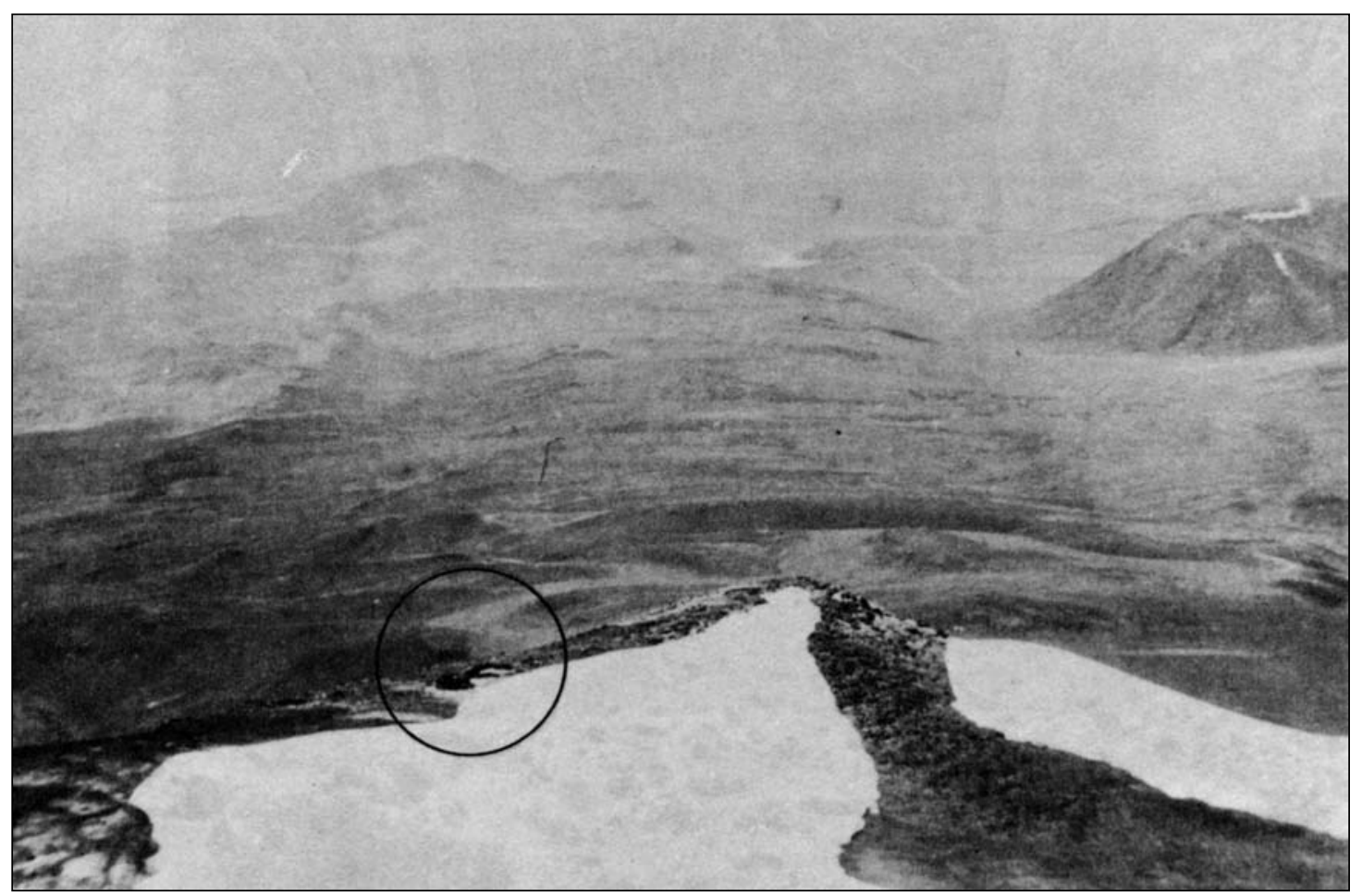

Figura 7. Vista tomada desde la cumbre principal del Pular hacia el Salar de Atacama.

El círculo señala el lugar de las construcciones incaicas.

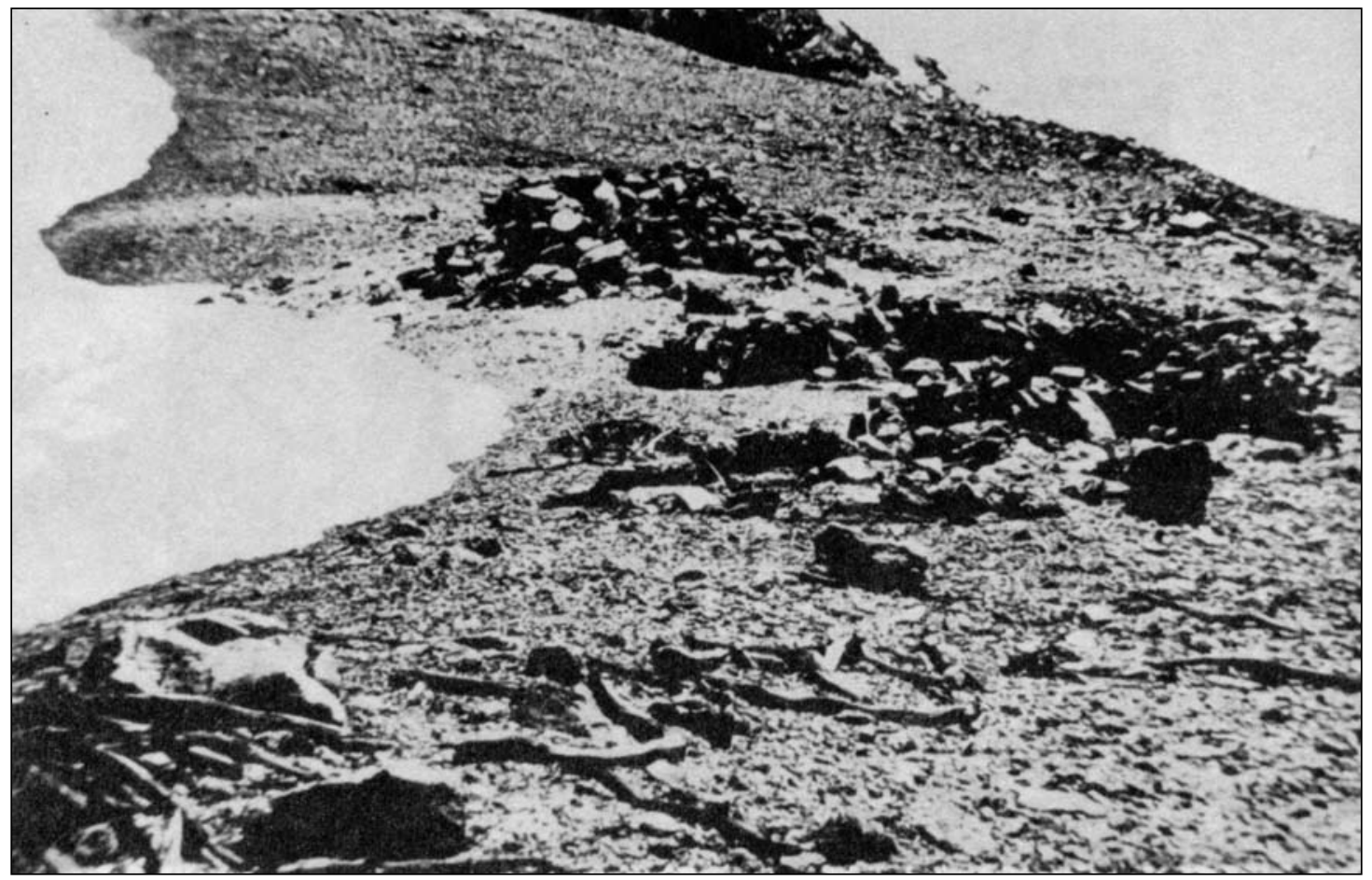

Figura 8. Una vista general del conjunto ceremonial incaico en la cumbre del Pular.

De izquierda a derecha, se encuentran: la casa del sacerdote, la pirca ceremonial y el fogón. 


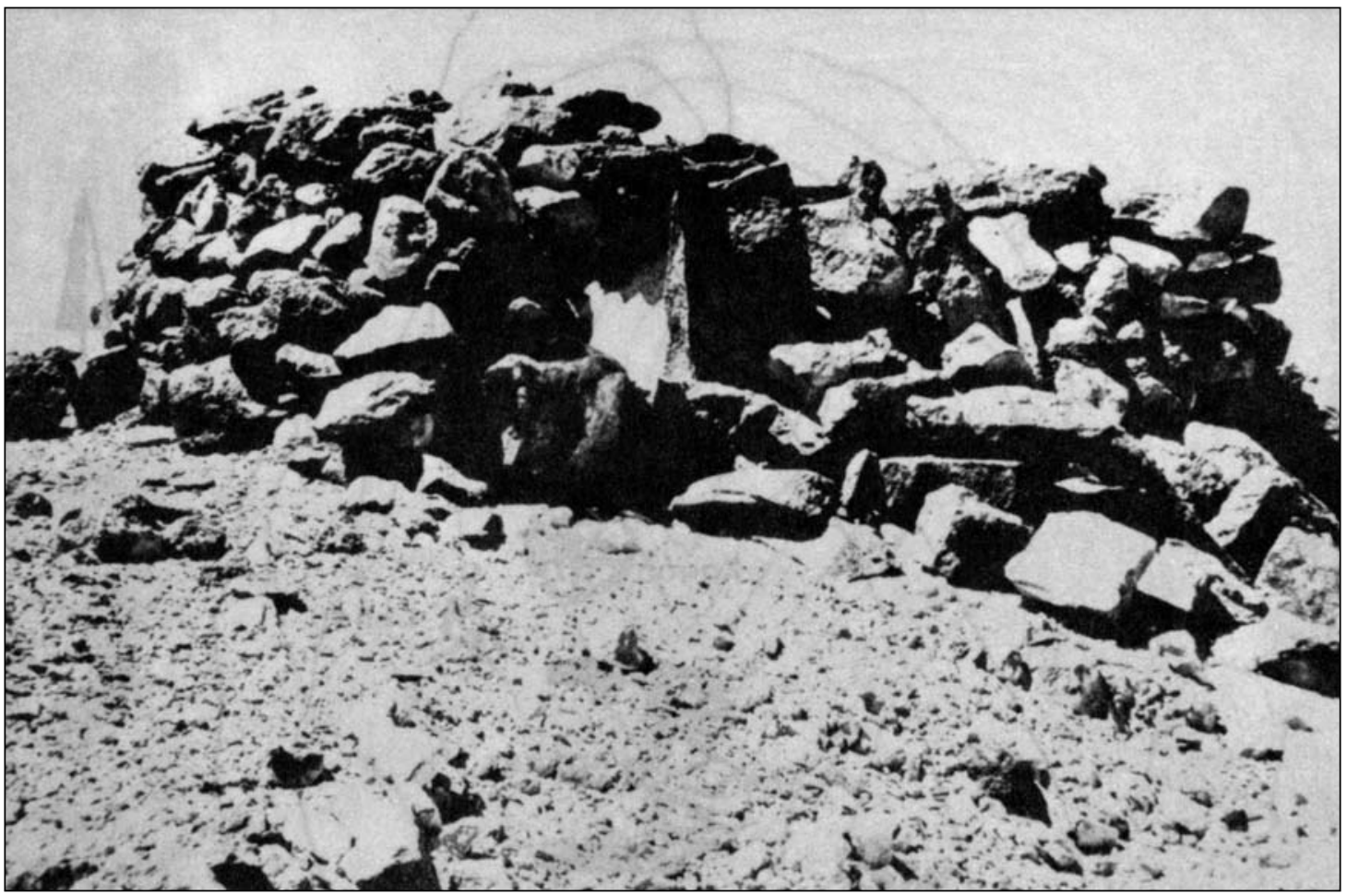

Figura 9. Casa del sacerdote de $1.70 \mathrm{~m}$ de altura. Se divisa claramente la puerta de acceso. En el interior hay nieve y restos de maderos que posiblemente correspondieron al techo.

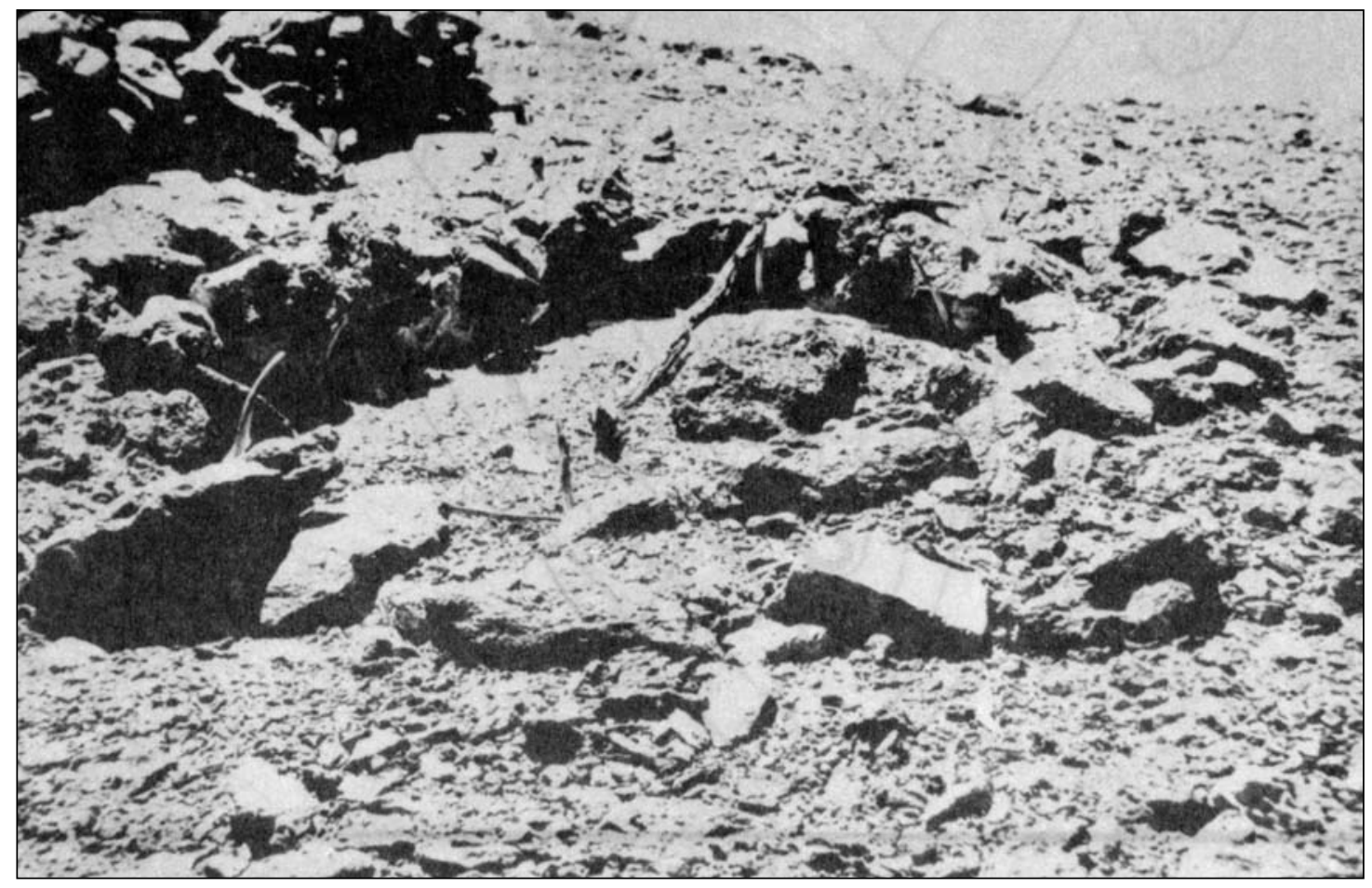

Figura 10. Fogón de $1.80 \mathrm{~m}$ de diámetro, con restos de leña en su interior. Al lado izquierdo que corresponde al sur, se observa el muro de piedra de la pirca ceremonial. 


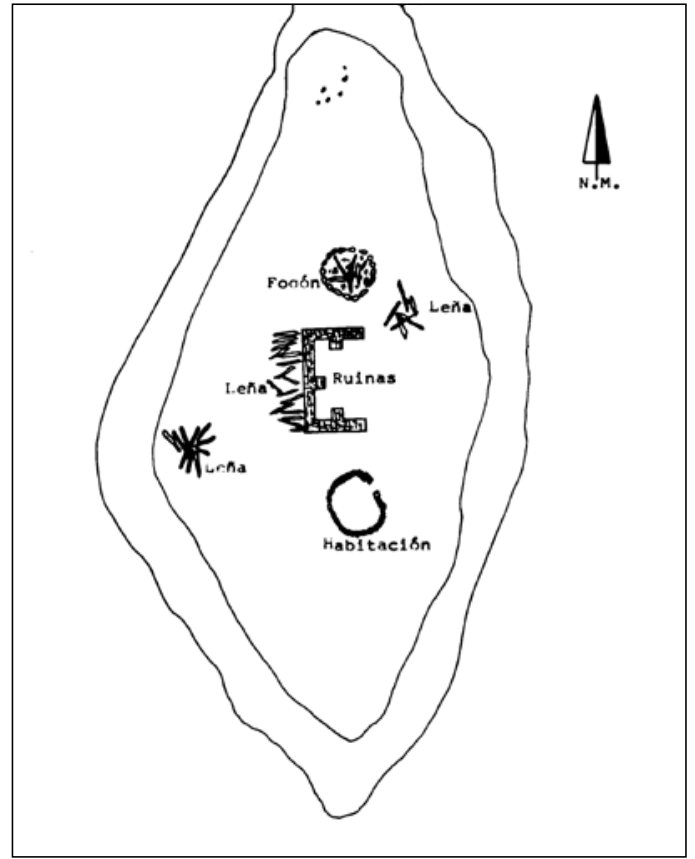

Figura 11. Croquis de la ubicación de las ruinas incaicas en la cumbre del Pular.

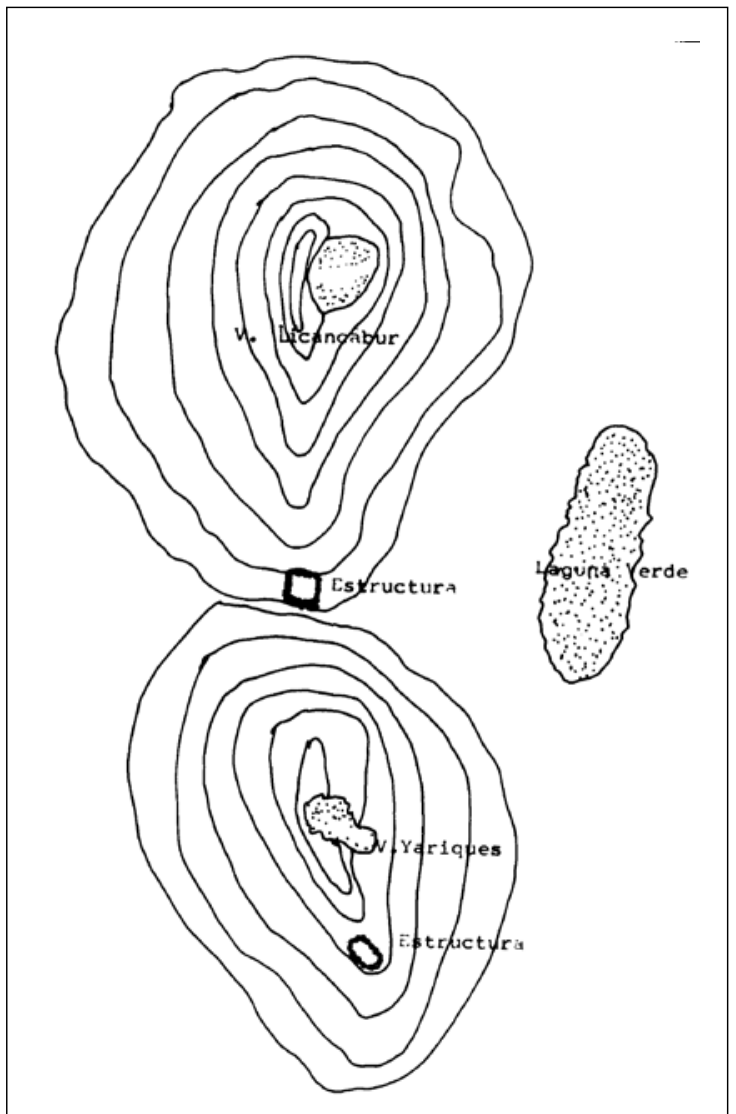

Figura 12. Ubicación de las estructuras en la subida del volcán Yariques y en la cima. 


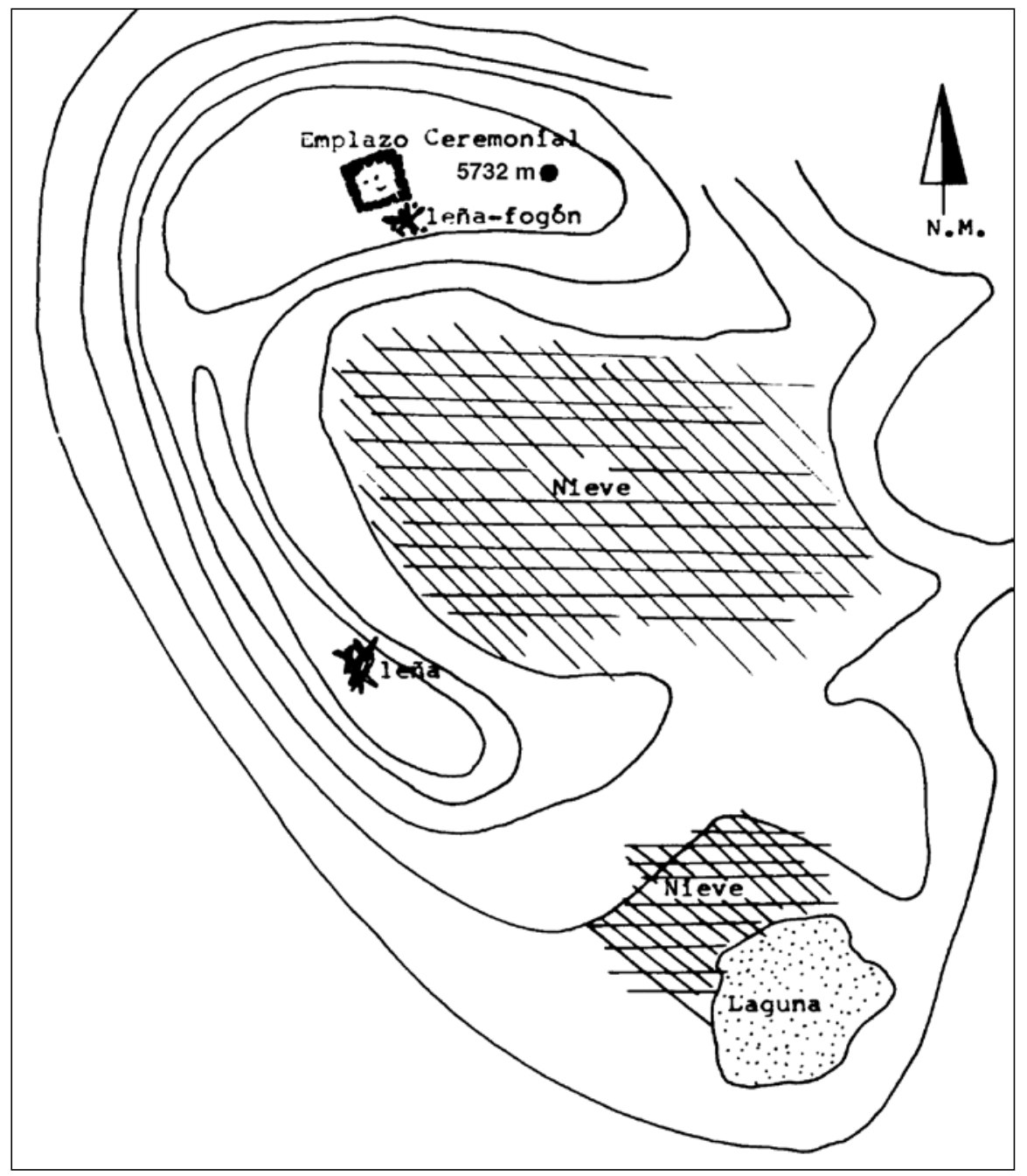

Figura 13. Croquis de la ubicación de las ruinas incaicas en la cumbre del volcán Colorado.

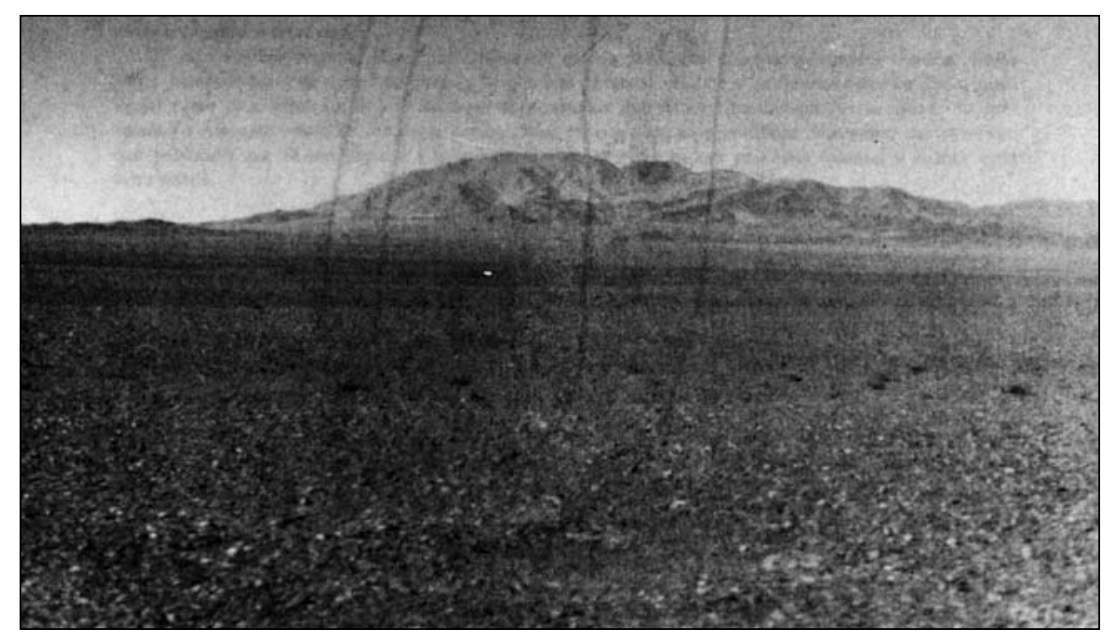

Figura 14. Vista panorámica del cerro Quimal, ubicado en la cordillera de Domeyko, al oeste del Salar de Atacama. 


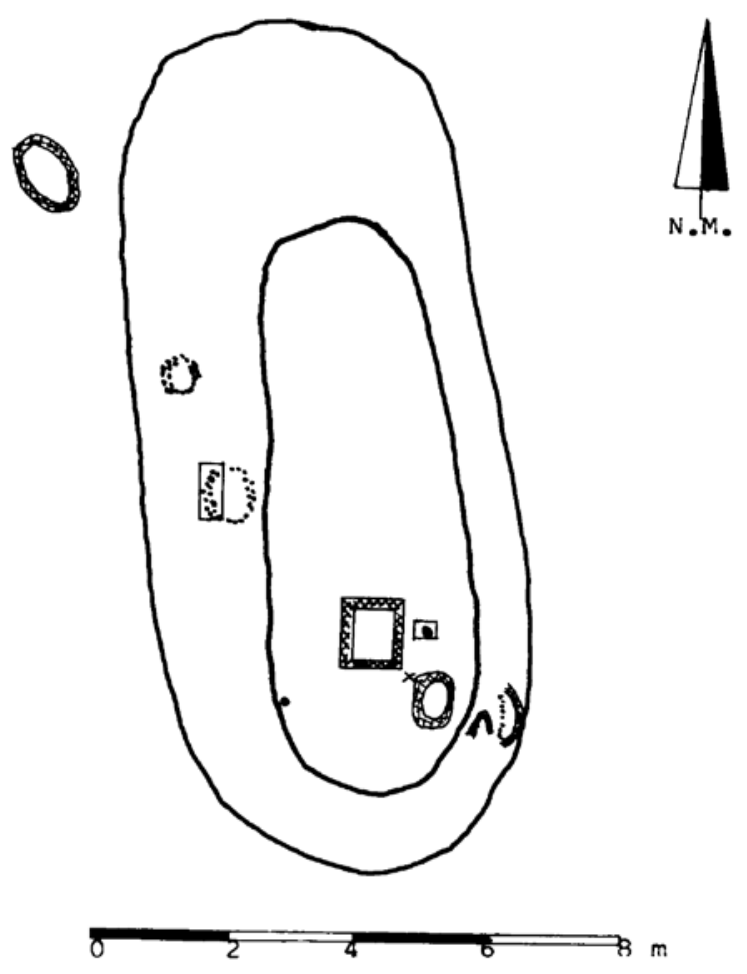

\section{LEYENDA}

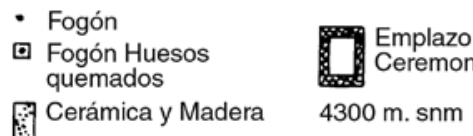

Figura 15. Ruinas en la cumbre del cerro Quimal, cordillera de Domeyko, San Pedro de Atacama.

hemos observado diversas estructuras, lo realmente común es la presencia de leña y la cerámica inca y de la época de las culturas locales sobrevivientes de San Pedro de Atacama.

Durante el dominio incaico se establecieron guarniciones administrativas, con un dominio pacífico con la población local. Sin embargo, a pesar de la poca evidencia cultural de las ocupaciones incaicas en esta región, nos llama la atención el hecho de que los incas hayan implantado su religión en las altas cumbres, demostrando que junto a la administración de la zona atacameña, se preocupaban de establecer su religión propia.

Creemos que sólo los sacerdotes subían a las cumbres acompañados de escasos ayudantes para oficiar las ceremonias al sol, que incluían los enterramientos de ofrendas bajo las plataformas. En el caso del Licancabur, la construcción del pueblo a sus pies, demostraría que la población pudo participar sólo en estos recintos bajos, los cuales fueron utilizados para funciones ceremoniales en ciertas épocas del año. Esto se ve muy bien por la presencia de cerámica y la ausencia de morteros y otros elementos de viviendas más permanentes.

De acuerdo a los registros de cerámica, es seguro que estas cumbres fueron adoradas como lugares sagrados durante tiempos incas. Pero deberemos estudiar mejor la posibilidad de que algunas cumbres como el caso del Quimal, se hayan utilizado en épocas algo más recientes. Esto lo deducimos por la presencia, en el Quimal, de una caja de cuero que parece pertenecer a una época de contacto con los españoles. Además, existe una leyenda local en 
la que se recuerdan toros como parte de la misma leyenda. El conjunto de cumbres parece ser parte de un sistema convergente bien observado desde el Quimal, el cual adquiriría una mayor importancia. Hasta ahora no se han encontrado evidencias de sacrificios humanos, pero sin duda que las cumbres eran adoratorios en las que se realizaban ofrendas en festividades anuales, para lo cual se ascendía fácilmente, sin las dificultades que ahora podríamos pensar que serían de riesgo o muy dificultosas. Hasta ahora los guías de la localidad pueden hacerlo varias veces en el día, como una acción normal.

\section{REFERENCIAS CITADAS}

LE PAIGE, G., 1975. Recuerdos de un andinista novicio de 72 años. Centro de investigaciones de Alta Montaña 2: 14-17.

1977. Recientes descubrimientos arqueológicos en la zona de San Pedro de Atacama. Estudios Atacameños 5: 109-124.
MOSTNY, G., 1949. Ciudades atacameñas. Boletín del Museo Nacional de Historia Natural 24: 125-201. 